\title{
Sub-national Energy Access Planning Model for Sustainable Development Goals: A Case Study of Barpak
}

\author{
Kshitiz Khanal $^{1, *}$, Bivek Baral ${ }^{2}$ \\ ${ }^{1}$ Open Knowledge Nepal \\ ${ }^{2}$ Kathmandu University, School of Engineering \\ Corresponding Email: khanal1990@gmail.com
}

\begin{abstract}
:
As most nations have adopted the Sustainable Development agenda to achieve the 17 Sustainable Development Goals (SDGs) by 2030, it is vital that planning of energy systems at local, regional and national levels also align with the agenda in order to achieve the goals. This study explores the sustainability of primary energy resources of a rural community to meet growing demands of the community, in order to achieve SDGs for energy access Goal no. 7 (SDG7) at local level. Using a linear back-casting techno-economic energy access model that informs the expected change in energy demand in order to reach SDG7 targets, this study examined whether local energy resources would be enough to achieve the targets for Barpak VDC (named such at the time of data collection before Nepal's administrative restructuring), and explored the possibility of importing electricity from national grid to attain SDG7 targets. By analyzing the outputs of the model for Barpak, we found that currently assessed local energy resources are insufficient to meet the energy access targets. Importing electricity from national grid, in addition to the mini-hydropower plant currently in operation at Barpak is needed to achieve the targets. Huge cost investment and timely expansion of transmission and distribution infrastructure is crucial. By 2030, total energy demand is expected to grow up to 50,000 Gigajoules per year. Electricity import from national grid grows steadily, reaching up to 45,000 Gigajoules in 2030. The social costs of energy will continue to be dominated by household sector till 2030, reaching up to 30 million Nepali Rupees per year in total. Use of wood as fuel, the only significant source of emission in the model is modeled to decrease linearly and stop by 2030, as required by SDGs. Emission of 17 Metric Tonnes of Carbon-dioxide and 4.5 million $\mathrm{kg}$ Methane equivalent is reduced to zero at 2030. This model serves as an innovative approach to integrate SDG targets to local and regional energy planning process, and can be adopted for energy systems and policy planning for various regions in Nepal.
\end{abstract}

Keywords: Energy Access, Multi-Tier Framework, Sustainable Development Goals

\section{Introduction}

$30 \%$ of Nepali population, most of them from rural Nepal, is estimated to be living in darkness [1]. Although the progress is significant in the recent divide, this figure doesn't represent the true reality of urban-rural divide in energy access. While $97 \%$ of urban population has electricity access, only $72 \%$ of rural population has access to electricity [2]. Alternative energy technologies such as micro-hydro, solar, biomass have enabled electricity access to $15 \%$ of the population [1]. These statistics indicate that Nepal has made significant progress in energy access in the recent decades, but such less granular statistics fail to portray a detailed picture of the level of energy services provided to the people, and how the energy services lead to developmental outcomes through productive usage and better livelihood.

It is widely accepted that energy access, or more specifically, electricity access is a key enabler of development, but electrification does not necessarily lead to poverty reduction or economic development [3]. Energy access when typically described in binary terms of presence or access to modern energy infrastructure, such as electricity access or access to non-solid cooking fuel fails to determine how access translates to reliable, affordable and modern services [4].

\subsection{Energy access models for sustainable development}

Energy modeling is a science as well as an art. While modeling is a technical concept, the level of details, number of parameters (aggregation and disaggregation) are for the model maker/s to choose, and these factors significantly affect the performance of the models. The choice depends of the experience of modeler and thus an art improved with experience. There can be numerous approaches to energy modeling, majorly due to the practical and theoretical issues. The practical issues 
include availability of data, varying prices of energy with time and geography, errors in income data, and problems in deflation of economic variables. Conceptual/theoretical issues include choice of model not fitting the objective of model, choice between top down and bottoms up approach, use of mathematical concepts, difference in social and physical systems, and learning effects. Energy models are not universal and energy modeling, like every other modeling practice is a trade-off between precision allowed by complexity and practicality allowed by simplicity.

The concept of integrated energy planning was proposed by IEA in 1970s, and have been defined by Mirakyan \& Guio [5] as "Regional (sub-national) integrated energy planning is an approach to find environmentally friendly, institutionally sound, social acceptable and cost-effective solutions of the best mix of energy supply and demand options for a defined area to support long-term regional sustainable development. It is a transparent and participatory planning process, an opportunity for planners to present complex, uncertain issues in structured, holistic and transparent way, for interested parties to review, understand and support the planning decisions". The planning process was divided into four phases, namely, Phase I: Preparation and orientations, Phase II: Model Design and detailed analysis, Phase III: Prioritization and decision, and Phase IV: Implementation and monitoring [5]. Integrated energy planning is important not only for countries but are becoming increasing important for sub-national territories, cities, and rural areas.

The balance of energy demand and energy supply was the basis of the first energy models, leading to the energy accounting models, which remain popular till date [6]. Reference Energy System were created based on the supply demand balance to represent all aspects of the energy system. This method was developed by Hoffman and it allowed for optimization of the energy system by analyzing alternative pathways in fulfilling the demand [7]. The common optimization method is linear optimization. National level optimization models like Brookhaven Energy System Optimization Model (BESOM) for USA, ENERGETICOS for Mexico, and generic models like Energy Flow Optimization Model (EFOM) and Market Allocation Model (MARKAL) have been developed for optimization of reference energy system.

Two distinctively different energy system models, useful in their own rights, are top-down and bottoms-up approaches of modeling. Top down approaches consider the effect of economic factors like GDP, price changes in the energy system and make calculations accordingly from the top to the end use. In contrast, bottoms-up approach is more inclined with technology and starts with the actual end use and goes higher up the reference energy system.

Environmental and climate change consideration in energy system models came to focus in the 1990s [7]. Features of actual energy system in energy system model for developing countries is carried inaccurately and more so in econometric and optimization models than accounting models like LEAP [7].

The common energy modeling methodologies according to Bhattacharya \& Timilsina [7] are:

- Bottom-up, optimization-based models (such as EFOM, MARKAL)

- Bottom-up accounting models (such as LEAP)

- Top-down econometric models

- Hybrid models

- Electricity system model (such as WASP)

Energy system models can be built on top of popular models like MARKAL obtained as desktop software. Packages like MARKAL are costly, where packages like OSeMOSYS are free and open source. Packages like LEAP are free to academics and developing country researchers but available to consultants for a price.

Acknowledging the crucial role of energy in sustainable development, Goal number 7 (SDG7) of the globally accepted Sustainable Development Goals aims to "ensure access to affordable, reliable, sustainable and modern energy for all" [8]. To measure progress in the goal, a Global Tracking Framework (GTF) has been developed under the UN's SE4ALL initiative. Based on the GTF, Energy Sector Management Assistance Program (ESMAP) developed the Multi-tier Framework (MTF) to monitor and evaluate energy access by following a multidimensional approach. MTF redefines energy access from the traditional binary count to a multi-dimensional definition as "the ability to avail energy that is adequate, available when needed, reliable, of good quality, convenient, affordable, legal, healthy and safe for all required energy services" [4]. Adoption of a framework such as the MTF helps in broadening the definition of energy access: from energy infrastructure to energy services to energy use. Connection of the framework to SDGs ensures that the framework can be useful to achieve as well as measure progress in SDG7. 
SDGs, once popularly remarked as "to-do list for people and planet, and a blueprint for success" by former UN secretary general Ban Ki Moon and widely accepted by nations around the globes serve as goals to be achieved by the world. This also allows for comparison between nations on the progress made towards SDGs. One common criticism of Millennium Development Goals (MDGs), the precursor to SDGs, was that they overlooked individual nationals and regional needs and did not include issues such as limited capabilities of governance [9]. These issues were factored in the SDGs, where national and local adoption of the goals is emphasized [10].

Nepal, as a signatory of SDGs needs to implement the goals at local level, and monitor and report progress. National Planning Commission of Nepal has developed a plan for sustainable distributed generation and grid access to all by 2022. This plan aligns with SDG7 to strive for universal access to modern sources of clean energy by 2030 [1]. This research addresses the need of planning energy access at subnational level by developing a linear back-casting techno-economic model to achieve Tier 5 energy access by 2030 . The model is implemented for Barpak, Gorkha.

Barpak VDC, selected as case study for this research is located in the northern part of Gorkha District of Nepal. Barpak resides at an elevation of $1900 \mathrm{~m}$ from sea level. It has a population of 4,985. There were 1,069 households and 4,985 people in Barpak VDC according to National Population and Housing Census 2011. The number is currently about 1400 households.

It was badly affected by Nepal Earthquake 2015. Barpak was the place where Nepal's first micro-hydro power plant was installed. The reason for choosing Barpak for the case study is availability of data regarding energy resources like micro hydro, solar energy and biomass gasification, interest of stakeholders from the area, and potential for future collaboration and studies.

Government of Nepal has formulated Rural Energy Policy in 2006 that acknowledges different renewable energy technologies that can be used to provide energy access in rural areas [11]. The policy, however, fails to address how intermittencies of different renewable energy resources will be tackled to provide sufficient amount of uninterrupted supply of energy at the time of need in required form.

The problem of rural energy access has technical, social, economic, as well as institutional dimensions that are continuously interacting with each other. These complex interactions need to be understood and taken into account to design energy plans, policies, programs, and systems for rural energy access. This demonstrates a need of creating a holistic model of rural energy system that can be used to design rural energy supply system, and also be used as a reference to formulate rural energy plans, policies, and programs.

Adoption of SDG framework for energy planning has started to gain attention in scholarly literature. Energy access, because of its crucial role in sustainable development, has relevance to other SDGs as well. 113 out of 169 SDG targets require actions to change energy systems, and has relationships with 143 targets in efforts to achieve SDG7 [12]. The MTF approach to achieve multiple tiers of energy access was explored for Suro Craic, Timor Leste. The model that estimated the cost of energy access to achieve SDG7 found that achieving Tier 5 of energy access could be up to 75 times costlier than achieving Tier 1. A least-cost model developed to inform decision making on energy mix to achieve SDGs, with a case study in Nigeria and Ethiopia suggests that energy access targets influence technology choice in regional energy systems. This study takes a similar approach of creating energy access planning model for subnational level, with a case study for Barpak in rural Nepal and presents the least-cost optimized scenario for choice of technologies in the energy-mix of primary and secondary resources.

In the remaining sections of this article, Methodology will be presented in section 2, Results and Discussion in section 3, and Conclusion and Recommendations in section 4 .

\section{Methodology}

Primary energy resources and current energy demands were assessed in order to mark a baseline for model based on Multi-tier framework. A linear back-casting model was created with SDG7 targets as end goals. Costs, emissions, and transitions pertaining to the scenario were modeled in LEAP, also utilizing the embedded OSeMOSYS model for least cost optimization.

Energy needs were calculated using a questionnaire survey of current accounts of energy consumption. Same accounts were projected to linearly grow at a fixed rate over the years. For local energy resources, secondary data for micro hydro resources were collected from local agencies, solar energy potential was estimated using public data from NASA's satellites, and data for biomass resources were estimated using data from local 
community forest. The potential of resources to fulfill demands of present and future were estimated using the model created in LEAP according to various scenarios developed by consulting energy sector experts and local stakeholders after review of available energy policies. The selected scenarios were subjected to least cost optimization using OSeMOSYS, integrated by default in recent versions of LEAP. The optimization was intended to show the potential of local resources to fulfill energy needs of present and future, and the additional cost of energy imports for the demand unmet by local resources under predefined constraints of environmental impacts.

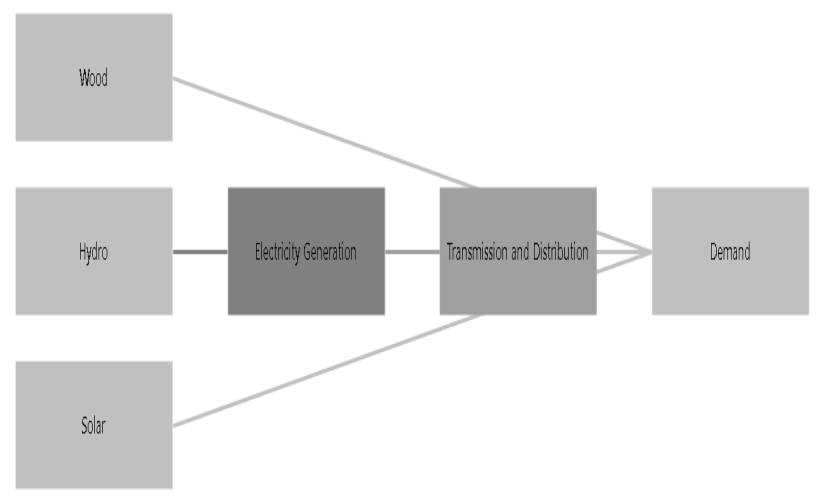

Figure 1: Simplified reference energy system model

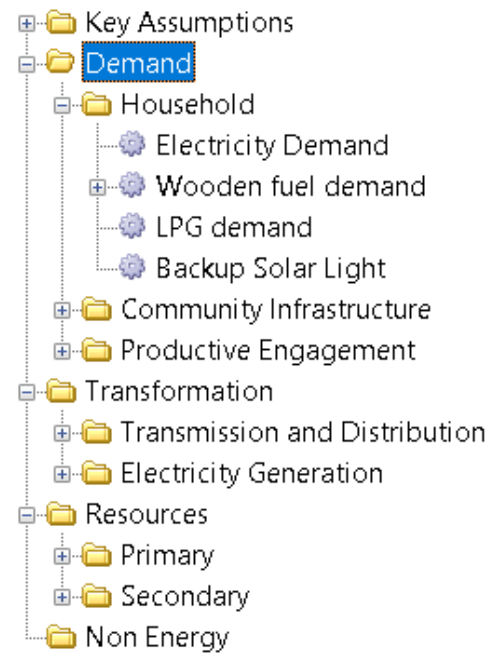

Figure 2: Simple branching of the model

Energy demand was modeled by branching into three sub sectors of energy use in a community, namely: Household demand, Productive Engagement, and Community Infrastructure. Electricity generation for micro hydro was modeled in a single branch of Transformation called Electricity Generation. Transmission and Distribution of central utility was modeled in a single module. Distributed solar electricity generation and distribution was modeled separately as Self Generation. Resources were modeled as Primary and Secondary. Primary resources refer to the indigenous resources and secondary resources refer to imported energy resources.

All subsectors of demand were divided into 6 levels of energy access defined in the SE4ALL framework ranging from Energy Access Tier 0 to Energy Access Tier 5. Households and other individual units of demand subsectors were placed into respective energy access levels according to the current accounts. The categorization is based on the matrices in multi-tier energy access framework.

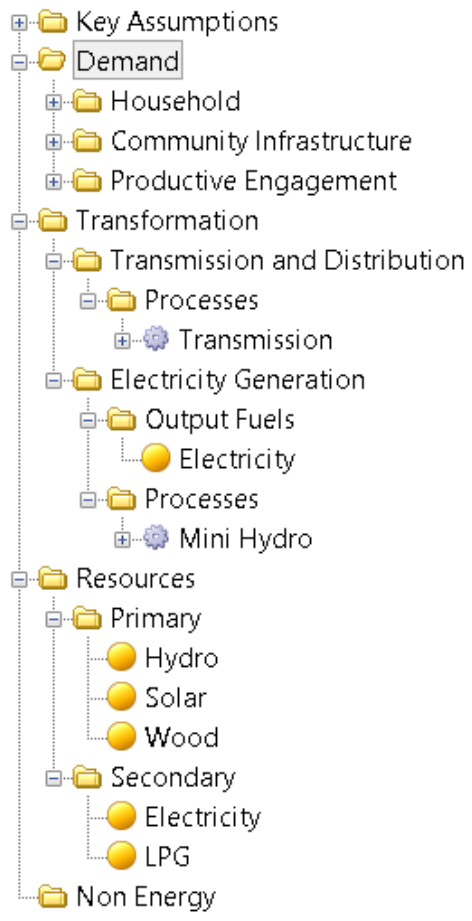

Figure 3: Detailed Branching of Transformation and Resources Modules

\section{Results and Discussion}

\subsection{Electricity access in Barpak in $\mathbf{2 0 1 5}$}

Considering household electricity supply as the main criteria to determine the tier of energy access in Barpak, the energy access in Barpak was found to be in Tier 2. Considering Household electricity services, energy access level of Barpak is Energy Access Tier 2. While we consider the household electricity consumption, we can find that the level of energy access is only at Tier 1. Nepal, when compared to other countries, belongs to the nations that have one of the lowest per capita energy consumptions. The trend is seen in Barpak too in the sense that while other energy access parameters point Barpak to be in Tier 2, when we calculate for actual electricity consumption, the energy access tier is 1 , compared to Tier 
1 when we consider other parameters like electricity supply and electricity services.

For productive engagements, the daily power supply when divided in the ratio of units consumed by the household and industrial clients in a typical month, the minimum wattage per client is between $200 \mathrm{~W}$ and $800 \mathrm{~W}$. Typical sources is a mini-hydropower supplied using a mini grid. These criteria make the access to electricity for productive engagements in Barpak a case of Tier 3 of multi-tier framework.

There are few street lights in the neighborhood, and they cover less than $25 \%$ of neighborhood. This makes the energy access of Tier 1 for access to street lighting.

Community institutions like health posts, schools are similar to households in Barpak because no dedicated electricity supply is provided to these institutions. The electric appliances used are no more specialized than household appliances. The use of equipment like computer in school was rare. Based on the criteria for community institutions, the energy access in Barpak for community institutions is in Tier 2, similar to household electricity supply.

While all houses have access to electricity and backup solar lights, only $60 \%$ of the houses use LPG for cooking and $50 \%$ of the houses use firewood for cooking. A significant proportion of houses use both wood and LPG, and sometimes even electric cooking.

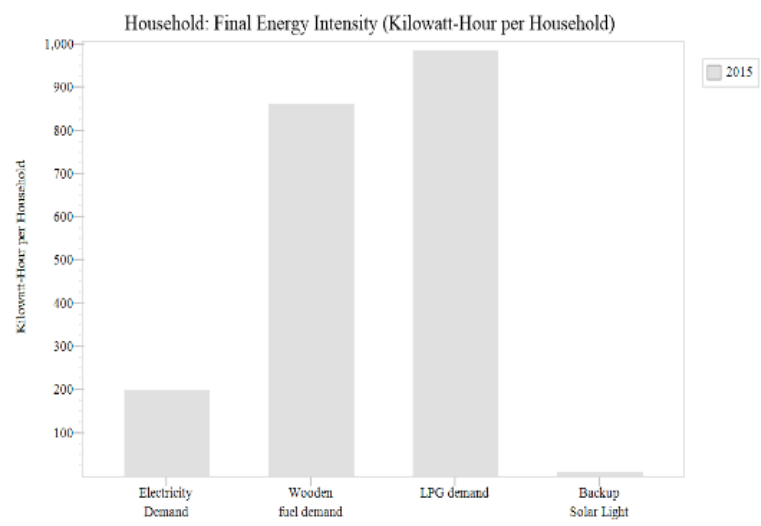

Figure 4: Final energy intensity of household

Contrary to households, not many community infrastructures use LPG, but use of other energy sources are comparable to household uses. Use of LPG is in higher proportion in productive engagements than in households.

Annual energy intensity per households is significantly high for wood and LPG, compared to electricity and backup solar light.

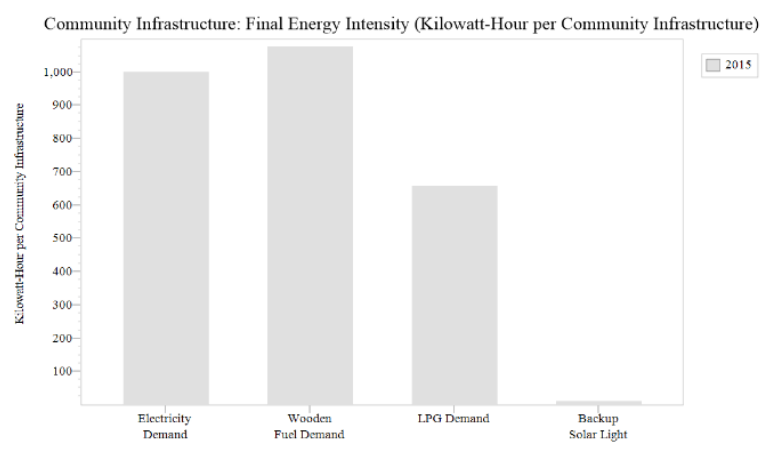

Figure 5: Final energy intensity of community infrastructure

However, since saturation of LPG is lower for community infrastructures when compared to households, annual energy intensity is higher for electricity and wooden fuel, compared to LPG and backup solar light.

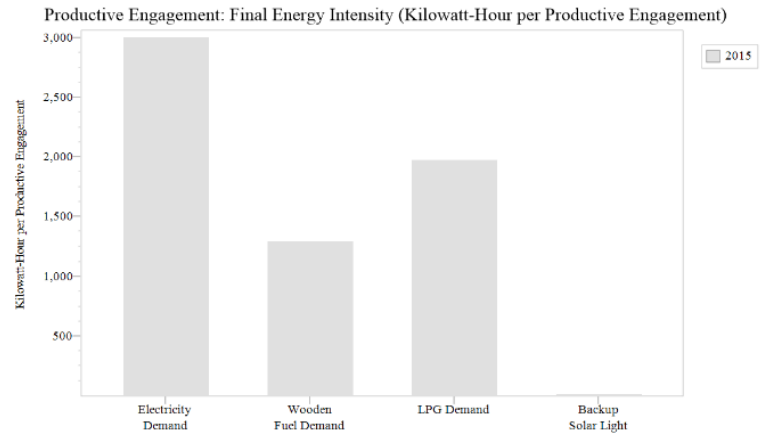

Figure 6: Final energy intensity of productive engagement

Since productive engagements heavily use electricity (e.g. in furniture), and significantly use wood and LPG both (e.g. in tea houses), energy intensity for electricity is the highest, but energy intensity for LPG and wood also on the higher side.

\subsection{Least cost optimization scenario}

To meet the targets set by the Sustainable Development Goals (SDGs), a scenario is created in which use of wood as a fuel becomes zero at the end of 2030. Access to electricity and backup solar light are already saturated at $100 \%$, and use of LPG (recognized as a modern non-solid cooking fuel) is expected to grow up to $100 \%$ saturation by the end of 2030. The scenario is same for households, productive engagements and community infrastructure.

Electricity demand will be the highest in 2030, reaching up to $4000 \mathrm{kWh}$ per year per households. Similarly, LPG demand will continue to grow steadily, while demand of wooden fuel is expected to be reduced to nil to meet the SDGs. While the actual energy intensities may vary, the 
trend is comparable for households, productive engagements, and community infrastructures.

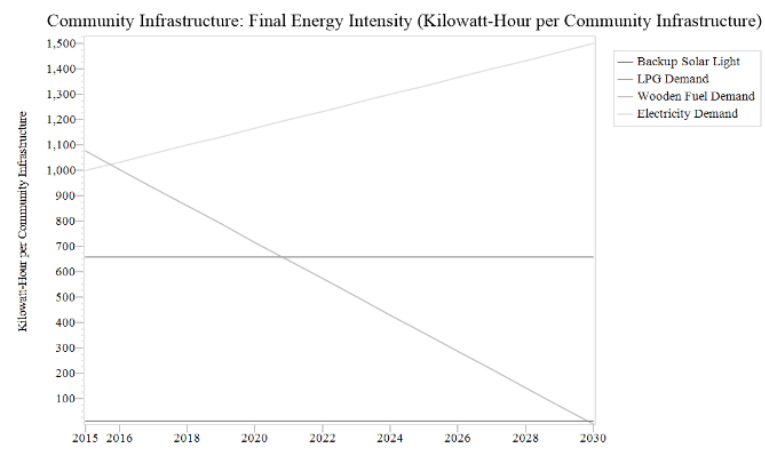

Figure 7: Final energy intensity of community infrastructure over the years

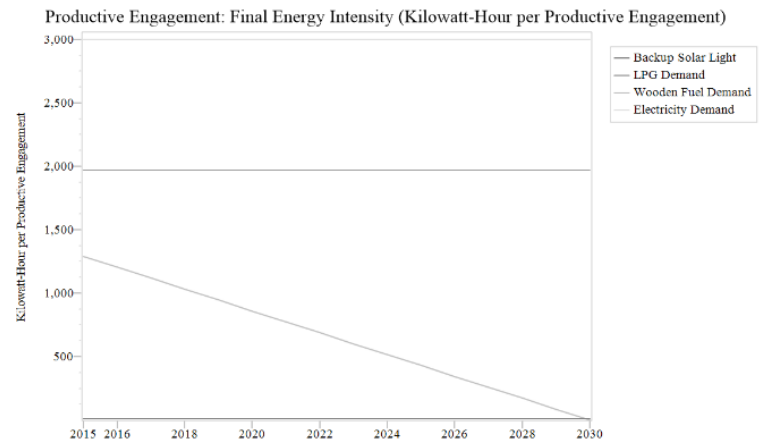

Figure 8: Final energy intensity of productive engagement over the years

According to the scenario modeled in this exploration, and since the number of households is significantly larger than the number of community infrastructures or productive engagements, household demand will increase to cover a much greater proportion in 2030 than community infrastructures and productive engagements. After breaking down the results for energy demand further, it can be observed that Household electricity demand, followed by household LPG demand are the large contributors. Similarly, household wood fuel demand is high at first, but is reduced yearly to reach zero by year 2030. By 2030, total energy demand is expected to grow up to 50,000 Gigajoules per year.

As scenario has be created such that if the local resources cannot fulfill the local energy demand, energy will be imported. Since Wood fuel and solar resources are assumed to be unlimited, only remaining imports are LPG and electricity. As reported during data collection, the most likely future reality in Barpak is to connection to national grid in a few years, electricity import has been calculated. The figure shows that electricity import will grow steadily, reaching up to 45,000 Gigajoules per year in 2030 .

Since the primary resources are constant, based on available data, the proportion of secondary resources to fulfill the total energy demand will continue to increase. Electricity will be the biggest secondary energy requirement, followed by LPG, as shown in the figure below.

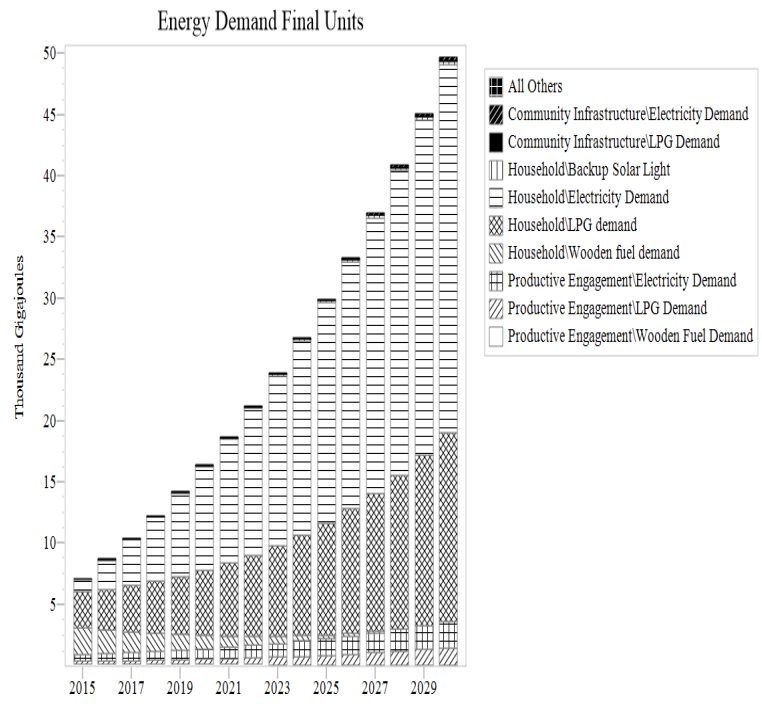

Figure 9: Energy demand final units' breakdown

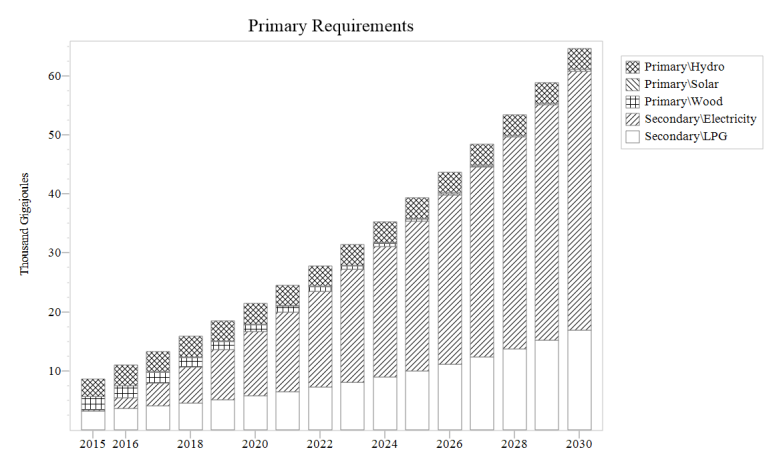

Figure 10: Primary energy requirements

The three major primary resources are Hydro, Solar and Wood fuel. Hydro usage for electricity generation is expected to be constant. Since number of households is increased, the usage of solar for backup solar lighting will increase steadily. To meet the SDG of clean fuel, usage of wood as fuel should be reduced to zero by 2030 . Because of which, we can see the decreasing usage of primary resources in the energy system.

As we saw in the diagrams above, energy demand, primarily for household electricity will increase significantly with population growth. Since the primary 
resources to generate electricity is limited, self-sufficiency regarding hydro resources would decrease, starting with the earlier years. Self-sufficiency with solar remains understandingly high at $100 \%$, and same for wood as wood use is modeled to reduce over the years.

The total social costs of energy will continue to be dominated by household sector till 2030, reaching up to 30 Million Nepali Rupees per year in total.

Similarly, since wood is the only source of significant emission in this model, and the use of wood fuel is modeled to decrease to zero by 2030 , as required by SDG targets, a linear decrease of 17 Metric Tonnes of $\mathrm{CO}_{2}$ equivalent in 2015 is seen to be reduced to 0 by 2030 .

\section{Estimation of methane equivalent}

According to Bhattacharya [13], emission factor $(\mathrm{g} / \mathrm{kg})$ Methane for Nepali two pot ceramic stoves, the most common stove found in Barpak, is $29.5+/-6.6$.

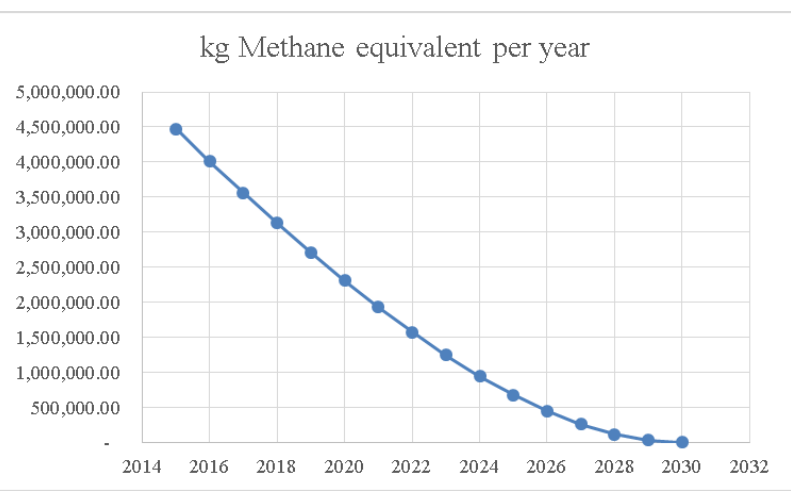

Figure 11: Kilogram of methane over the years

The results show that, in order to achieve the energy access targets, set in the Goal no. 7 of the SDGs, there needs to be a steady growth of energy access demand as well as investments in energy system. If Nepal were to achieve the SDGs by 2030, there needs to be huge growth rate of energy demand in household, productive engagement, as well as the community infrastructure.

Since the hydro capacity of all local resources has not been estimated, currently available hydro-resources will not fulfill the growing energy demand, if we were to meet SDG targets. Solar resources are assumed infinite, and wood demand is expected to decrease to meet clean fuel targets of SDGs.

It is good practice to verify results of mathematical models. Validation of models like this can be checked by validating face validity, structural and data assumptions, and validating output-input transformation. Since outputinput transformations cannot be checked because of unavailability of output and input data, the ways to validate the model include checking the logical soundness of a model to an expert (face validity), and checking all the assumptions (structural assumptions and data assumptions).

In both of these cases, the validation of these have to be carried out by an expert, owing to the nature of the model. All structural and data assumptions are explicitly listed in the description of the model, and were subjected to advisors and supervisor of the project.

Another way to validate such models can be comparing with similar research. As similar studies could not be found in current literature, such validation could not be done.

\section{Conclusion and Recommendations}

In this study, we created a back-casting energy access model for a rural community. By incorporating data collected for present energy demand, available data of local energy resources, and targets of achieving Goal number 7 of the SDGs into the model, we explored whether local resources will be able to fulfill growing energy demands. We also estimated the amount of energy (electricity) that needs to be imported to meet the growing energy demands, and the investments needed to achieve the goal.

We have thus created a parametric model that can be used to assess the self-sufficiency of local resources and plan infrastructure development to achieve the energy access target of SDGs. This model can be used for similar assessments of subnational regions.

Similarly, by analyzing the outputs of the model for Barpak, we found that currently assessed local energy resources may not be enough to reach the energy access targets. Importing electricity from the national grid is a possibility that will help in reaching the energy access targets of Goal number 7 of the SDGs. Huge cost investment and timely expansion of transmission and distribution infrastructure is necessary in order to meet the SDGs target by 2030 .

The study had several limitations, which, if addressed can increase the reliability of the model. While this study used a single year data as baseline, using a baseline of 2-3 years helps improve the model.

\section{Acknowledgments}

The authors are grateful to Kathmandu University, School of Engineering, Department of Mechanical Engineering for facilitating this research. The authors also appreciate 
the assistance provided by Saurav Dhakal, Mr. Bir Bahadur Ghale, Mr. Guna Raj Dhakal and the kind people of Barpak.

\section{References}

[1] “Universalizing Clean Energy in Nepal,” National Planning Commision, 2018.

[2] Asian Development Bank, NEPAL ENERGY SECTOR ASSESSMENT, STRATEGY, AND ROADMAP. 2017.

[3] S. C. Bhattacharyya, "Energy for Sustainable Development Energy access programmes and sustainable development : A critical review and analysis," Energy Sustain. Dev., vol. 16, no. 3, pp. 260-271, 2012.

[4] M. Bhatia and N. Angelou, "BEYOND CONNECTIONS Energy Access Redefined," 2015.

[5] A. Mirakyan and R. De Guio, "Integrated energy planning in cities and territories : A review of methods and tools," Renew. Sustain. Energy Rev., vol. 22, pp. 289-297, 2013.

[6] K. C. Hoffman and D. Wood, "Energy System Modeling and Forecasting," Annu. Rev. Energy, 1976.

[7] S. C. Bhattacharyya and G. R. Timilsina, "A review of energy system models," Int. J. Energy Sect. Manag., vol. 4, no. 4, pp. 494-518, 2010.

[8] "Sustainable Development Goal 7." [Online]. Available: https://sustainabledevelopment.un.org/sdg7.

[9] M. Fehling, B. D. Nelson, and S. Venkatapuram, "Limitations of the Millennium Development Goals : a literature review," Glob. Public Health, vol. 8, no. 10, pp. 1109-1122, 2013.

[10] European Commission, "Delivering the Sustainable Development Goals at local and regional level," 2018.

[11] G. of N. Ministry of Environment, "Rural Energy Policy, 2006," 2006.

[12] F. F. Nerini et al., "Mapping synergies and trade-offs between energy and the Sustainable Development Goals," Nat. Energy, vol. 3, no. January, 2018.

[13] S. C. Bhattacharyya, "Energy Access and Development," 2013. 